\title{
Strategies for Design-Build in Korea Using System Dynamics Modeling
}

\author{
Moonseo Park, M.ASCE${ }^{1}$; Sae-Hyun Ji²; Hyun-Soo Lee, M.ASCE ${ }^{3}$; and Wooyoung Kim ${ }^{4}$
}

\begin{abstract}
Increasingly adopted by both public and private organizations, design-build (DB) has become a favored construction project delivery system, outperforming other systems in terms of cost, schedule, and quality. However, DB has been especially criticized by the public sector for practicing subjective evaluation, for requiring excessive resources, and for providing only limited accessibility to small and medium-sized contractors. In Korea, similar critiques have been raised, as these qualities have prevented public owners from benefiting from the potential advantages of DB. In order to address these challenging issues, the present research systematically analyzes the characteristics of the DB delivery system in Korea. Based on industry surveys and an extensive literature review, a qualitative system dynamics model is developed and used to propose and test hypothetical DB policy alternatives which are expected to enhance DB performance. Furthermore, after the appropriate customization processes, these research findings can also be applied to the industry settings of different countries.
\end{abstract}

DOI: 10.1061/(ASCE)CO.1943-7862.0000095

CE Database subject headings: Project delivery; Design/build; Turnkey projects; Korea, South; Construction management.

\section{Introduction}

Having become one of the preferred construction project delivery systems, design-build (DB) has been increasingly used by public agencies. Accordingly, over the years, many studies have been conducted to examine its effectiveness. For instance, Konchar and Sanvido (1998) have analyzed the performance (in terms of cost, schedule, and quality) of three different project delivery systems (in 351 U.S. building projects): Design-Bid-Build (DBB), DB, and Construction Management. These case studies demonstrate that, in most cases, DB yields excellent results. The U.S. National Institute of Standard and Technology (NIST) (Thomas et al. 2002) has also reported that projects using the DB system significantly outperformed those using DBB in terms of schedule, change, rework, and practice use performance. However, as reported by the U.S. Legislative Analyst's Office (LAO 2005), the DB system has encountered criticism for being subjective in evaluation, and for being limited in its accessibility to small and medium-scale contractors.

These issues have also been raised in Korea. Since DB's in-

\footnotetext{
${ }^{1}$ Associate Professor, Dept. of Architecture, Seoul National Univ., San 56-1 Shinrim-dong, Seoul, Korea (corresponding author). E-mail: mspark@snu.ac.kr

${ }^{2}$ Ph.D. Student, Dept. of Architecture, Seoul National Univ., San 56-1 Shinrim-dong, Seoul, Korea. E-mail: oldclock@snu.ac.kr

${ }^{3}$ Professor, Dept. of Architecture, Seoul National Univ., San 56-1 Shinrim-dong, Seoul, Korea. E-mail: hyunslee@snu.ac.kr

${ }^{4}$ Researcher, Construction and Economy Institute of Korea, 71-2 Nonhyun-dong, Seoul, Korea. E-mail: beladomo@cricmail.net

Note. This manuscript was submitted on February 22, 2008; approved on May 14, 2009; published online on May 16, 2009. Discussion period open until April 1, 2010; separate discussions must be submitted for individual papers. This paper is part of the Journal of Construction Engineering and Management, Vol. 135, No. 11, November 1, 2009. C)ASCE, ISSN 0733-9364/2009/11-1125-1137/\$25.00.
}

troduction in 1975, DB (locally called "Turn-Key") projects in Korea have steadily increased in number, accounting for $26 \%$ of public projects procured in 2005. This quantitative expansion has been attributed to Korean government construction policies such as the "Plan for Increasing DB Projects" (1996) and the "Plan for Increasing Efficiency of Public Projects" (1999). However, as these government initiatives only consider project scale and type in the selection of a delivery system (Seo 2003), they have met with considerable criticism. Additionally, only a few major contractor-led DB teams have been able to join the bidding process; this has, in fact, increased their market dominance, and has subsequently raised questions about the objectivity of the bidding and evaluation processes.

In any case, public owners in Korea have not been able to benefit from the potential advantages of DB. Furthermore, although this problem has been addressed by many studies, these studies have been limited in that they examine the origin of the problem from fragmented viewpoints; this results in only shortterm remedies. In contrast, the present study systematically analyzes the characteristics of the DB delivery system in Korea, and using a system dynamics modeling approach, it proposes DB policy alternatives.

To achieve these objectives, this study conducts a literature review in order to identify the general characteristics of the DB system. Then, delivery trends in the Korean public sector are investigated, and the causal relationships among the DB characteristics are interrogated through questionnaire surveys. Based on the research findings, a qualitative system dynamics model is developed to further examine the research issues surrounding DB and to analyze previously suggested policy initiatives and those proposed in this research. This study is relevant to both the construction industry and academia, as it provides a means of enhancing the performance of the DB delivery system and a quantitative basis for the systematic analysis of industrial issues. 


\begin{tabular}{|c|c|c|}
\hline $\begin{array}{l}\text { Delivery } \\
\text { system }\end{array}$ & Pros & Cons \\
\hline DBB & $\begin{array}{l}\text { A familiar system which is well tested }[(2),(6),(9) \text {, and } \\
(11)] \\
\text { Project is fully defined and low ambiguities before tendering } \\
{[(8),(9) \text {, and (11)] }} \\
\text { Competitive bidding results in lowest cost }[(8) \text { and }(11)] \\
\text { Relative ease of assuring quality control }[(8) \text { and }(11)] \\
\text { Objective contract award (8) } \\
\text { Good access for small contractors }(8) \\
\text { Owners do not necessarily have their own technical staff (9) }\end{array}$ & $\begin{array}{l}\text { Conflicts and disputes can easily arise }[(8),(9) \text {, and (11)] } \\
\text { Builder not involved in design process (8) } \\
\text { May be slower [(8), (9), and (11)] } \\
\text { Price not certain until construction bid is received (8) } \\
\text { Contract may likely have to be renegotiated (9) } \\
\text { Split responsibilities among participants (11) }\end{array}$ \\
\hline DB & $\begin{array}{l}\text { Generally applied for large and complex projects }[(1),(3), \\
(5),(6),(7), \text { and }(10)] \\
\text { Faster project delivery }[(2),(6),(8),(9),(10) \text { and }(11)] \\
\text { Outperforms in terms of cost and quality }[(1),(2),(4), \text { and } \\
(6)] \\
\text { Builder involved in design process }[(8) \text { and }(11)] \\
\text { Less conflicts and disputes }[(6),(7),(8), \text { and }(11)] \\
\text { Good coordination and communication }[(3),(9), \text { and }(11] \\
\text { Shortening lead time }[(1) \text { and }(11)]\end{array}$ & $\begin{array}{l}\text { Limited access for small contractors }[(8) \text { and }(10)] \\
\text { Subjective contract award(ing?) }[(3),(8),(10), \text { and }(11)] \\
\text { Excess use of resources for tendering }[(3) \text { and }(10)] \\
\text { Clearly defined performance standard must exist }[(1),(9) \text {, } \\
(10) \text {, and (11)] } \\
\text { Limited assurance of quality control }[(8),(9),(10) \text {, and }(11)] \\
\text { Difficulty for owners' in keeping up with the project }[(3) \text { and } \\
\text { (9)] }\end{array}$ \\
\hline
\end{tabular}

(6) Thomas et al. (2002); (7) Kim et al. (2007); (8) LAO (2005); (9) Gould (2005); (10) Levy (2006); and (11) Potts (2008).

\section{Literature Review}

\section{$D B$ versus $D B B$}

A project delivery system can be defined as the "relationship, roles, and responsibilities of project team members and the sequence of activities required" for the development of a capital project (Konchar and Sanvido 1998). DB and DBB are two of the most commonly used project delivery systems, and each has its particular advantages. While DB is cited as being effective for large-scale or highly complex projects (Seeley 1997; Thomas et al. 2002; Levy 2006; Kim et al. 2007; Ndekugri and Turner 1994; Molenaar and Songer 1998), DBB offers the checks and balances of a comprehensive delivery system in which risk is minimized through firm control of the design and construction processes (Thomas et al. 2002).

The evolution of DB-an industry-driven program aimed at developing a more effective project delivery system (Levy 2006) — can be traced throughout history. Indeed, it began as an outgrowth of a project delivery system dating back to pyramid construction in 1596 B.C. During the Renaissance, as project complexity increased, specialization in both design and construction was required for functional purposes. Then, as statutory and case law developed in the United States in the 19th century, the separation of design and construction gradually shifted from functional to legal. Thus, the traditional DBB project delivery system emerged as the primary system (Natkin 1994). DBB remained the standard delivery system of choice until the inflationary 1970s and litigious 1980s encouraged owner organizations to reevaluate it. In reality, the traditional DBB project often becomes a designbid-redesign-rebid-build project. Under this system, budgets prepared by owners tend to fall short of actual construction costs; this has resulted in expensive redesign work, has made it more difficult to implement value engineering, and has delayed project deliveries (Levy 2006). Consequently, various government bodies have examined the works of the construction industry, proposing project delivery systems such as DB, turnkey, and construction management which have emerged as viable alternatives to the more conventional DBB system (Ndekugri and Turner 1994).
Similarly, in the United Kingdom, for much of the 20th century, delivery systems have predominantly followed the traditional approach, which entails that clients engage with separate organizations for three key services: design, cost advice, and construction. However, this fragmentation was criticized by various U.K. reports examining the construction industry and attempting to make appropriate recommendations. Consequently, at this time, the DB approach became the most popular alternative to DBB (Ndekugri and Turner 1994).

Indeed, in the last 2 decades, DB has particularly experienced extraordinary growth (Songer et al. 1994, 1997; Lee 2006; Kim et al. 2007; Molenaar et al. 1999; Chan 2000; Akintoye 1993; Potts 2008). Such growth suggests that more owners are selecting DB for the first time. Also, an inevitable outcome of this growth is that more contractors and architects, with little or no DB experience, have been entering the market (Songer et al. 1994, 1997). Consequently, it has become necessary that owners with the appropriate technical expertise evaluate the qualifications of DB contractors and their proposed design approaches (Puerto et al. 2008).

As shown in Table 1, which summarizes the pros and cons of DB and DBB, it is difficult for small and medium-sized contractors to participate in DB bidding because DB is generally used in large, complex projects that require considerable technical skill. Furthermore, as DB projects have only been evaluated, before commencing construction, on the basis of schematic design, management planning, and track records, this has raised the issue of subjective evaluation, which has met with much criticism. Nevertheless, owners have generally been satisfied with overall DB performance, thus resulting in increasing utilization of DB (Molenaar et al. 1999).

According to the U.S. NIST report (Thomas et al. 2002), based on a data set comprised of 326 owner projects between 1997 and 2000 , the average DB project is larger than the average DBB project. This report also observes that the average cost of all DB projects was approximately four times larger than that of DBB projects ( $\$ 80.5$ million versus $\$ 22.7$ million). Furthermore, as construction projects have become megasized and increasingly 
complex, clients' requests have become more and more complicated. As different researchers have observed, this has subsequently resulted in a strong correlation between large projects and the tendency to select DB (Thomas et al. 2002; Kim et al. 2007; Seeley 1997; Levy 2006). The NIST report has also suggested, with regard to project performance, that the utilization of $\mathrm{DB}$ yields performance advantages to owners.

In addition, Konchar and Sanvido (1998) have asserted that, on average, DB outperforms DBB in terms of cost, schedule, and quality, which reflects the main results of the University of Reading's empirical study (Bennett et al. 1996). Ultimately, such findings reinforce the assumptions surrounding these two systems, such as the assumption that DB is an effective alternative to DBB, particularly for large-scale and complex projects. In short, owner satisfaction regarding DB performance (in terms of quality, cost efficiency, and time savings) has resulted in the considerable growth of DB projects. However, despite this quantitative growth (i.e., increasing number of DB projects) and qualitative growth (i.e., increasing positive opinion of DB), DB is still criticized for requiring excessive resources and for awarding contracts on a subjective basis; these criticisms have had a negative impact on the number of teams attending the bidding process. Based on the aforementioned literature, three major components and related factors which describe the current $\mathrm{DB}$ phenomenon can be extracted: DB performance, number of DB projects, and number of DB teams attending bid.

As previously discussed, it can be seen that DB and DBB are rivals to which should be chosen as the most appropriate delivery system. Until recently, DBB has won the majority of bids, but DB has posed a great challenge to this status. This is the context in which the questions of this study are established; these questions are as follows. First, what makes DB adoption increase? Second, despite the increasing utilization of $\mathrm{DB}$, what types of problems have risen around DB? Last, the DB process is considered to be efficient, meeting demands in a timely fashion; if this is so, which strategies could be developed to further enhance the DB delivery system?

\section{DB Practice in Korea}

In Korea, the introduction of DB into the public sector occurred in the mid 1970s and has been impacted by other nations' implementation of this delivery system. For example, in the United States, which introduced DB into the construction industry in the early 2000s, there has recently been a significant increase in the volume of DB projects. Similarly, in Korea, there has recently been a striking increase in the volume of DB projects. Based on a data set from the Construction Association of Korea (White Paper on Construction 2000-2006) and Park (2006) comprised of 15,934 public projects in 2005, it can be observed that the average cost of all DB projects has been larger than that of DBB projects (\$84,768.3 million versus \$1,461.9 million). Moreover, in the Korean public sector in 2000, DB projects only accounted for approximately $10 \%$ of the total construction volume. Since then, the number of DB projects executed by public agencies has been steadily increasing, and in 2005, 26\% of public projects (representing \$13 billion) were delivered using DB (White Paper on Construction 2000-2006; Lee 2006; Park 2006). Hence, it can be assumed that there are similarities in the United States and Korea in both environmental and project specifics of DB growth and adoption that affect construction procurement.

However, despite such an increase in the Korean public sector, only a few bidders have been able to participate in the DB bid-
Table 2. DB Market Dominance by Major Contractors (Park 2006; Rye 2006)

\begin{tabular}{|c|c|c|c|}
\hline \multirow[b]{2}{*}{ Year } & \multicolumn{2}{|c|}{$\begin{array}{c}\text { Bid attendant } \\
\text { (per project on average) }\end{array}$} & \multirow{2}{*}{$\begin{array}{l}\% \text { of public } \mathrm{DB} \\
\text { projects awarded } \\
\text { to top } 6 \text { contractors }\end{array}$} \\
\hline & DB & DBB & \\
\hline 2002 & - & - & 79.9 \\
\hline 2003 & - & - & 81.7 \\
\hline 2004 & 2.5 & 355 & 67.3 \\
\hline 2005 & 2.5 & 396 & 67.8 \\
\hline 2006 (as of October) & 2.5 & 536 & - \\
\hline
\end{tabular}

ding process. Over the past 3 years, the number of DB bidders, on average, has remained below three, while the number of DBB bidders has ranged from 355 to 536 (see Table 2). As a result, the top six Korean contractors have been awarded over $67 \%$ of public DB projects (Park 2006; Rye 2006). While these major contractors have enjoyed market dominance, there has not only been a consequent lack of diversity among successful DB teams, but public owners have also been prevented from benefiting from the advantages of the DB system. Therefore, to address these issues, this research aims at analyzing DB characteristics and mapping out alternative and innovative DB delivery strategies.

\section{Research Methodologies}

\section{System Dynamics}

System dynamics was developed in order to apply control theory to the analysis of industrial systems, and it has been used to analyze diverse industrial, economic, social, and environmental systems. One of the most powerful features of system dynamics is its capacity for providing analytic solutions for both complex and nonlinear systems (Kwak 1995; Sterman 2000). System dynamics is also useful for providing systematical explanations and policy alternatives that are often counterintuitive and discerning, and for elucidating problems and identifying feedback processes with causal loop diagrams. These loop diagrams consist of variables that are connected by arrows denoting the causal influences between variables. Each causal link is assigned a polarity, either positive $(+)$ or negative $(-)$, to indicate how the dependent variable is impacted when the independent variable changes. Table 3 summarizes the definitions of link polarity (Sterman 2000).

The dynamics of all systems arise from the interaction of two types of feedback loops: positive (reinforcing) and negative (balancing) (Sterman 2000). While positive loops tend to reinforce or amplify whatever is already occurring, negative loops counteract and oppose change. Taking an example from the study of Sterman (2000), the diagram in Fig. 1 represents the behavior of engineers trying to complete a project by a certain deadline. First, the engineers compare the work remaining to be completed with the time

Table 3. Link Polarity (Sterman 2000)

\begin{tabular}{|c|c|}
\hline Symbol & Interpretation \\
\hline $\mathrm{X}$ & $\begin{array}{r}\text { All else equal, if } \mathrm{X} \text { increases (decreases), then } \mathrm{Y} \text { increases (decreases) above (below) } \\
\text { what it would have been. In the case of accumulations, } \mathrm{X} \text { adds to } \mathrm{Y} .\end{array}$ \\
\hline $\mathrm{X}$ & $\begin{array}{r}\text { All else equal, if } \mathrm{X} \text { increases (decreases), then } \mathrm{Y} \text { decreases (increases) above (below) } \\
\text { what it would have been. In the case of accumulations, } \mathrm{X} \text { abstracts from } \mathrm{Y} .\end{array}$ \\
\hline
\end{tabular}




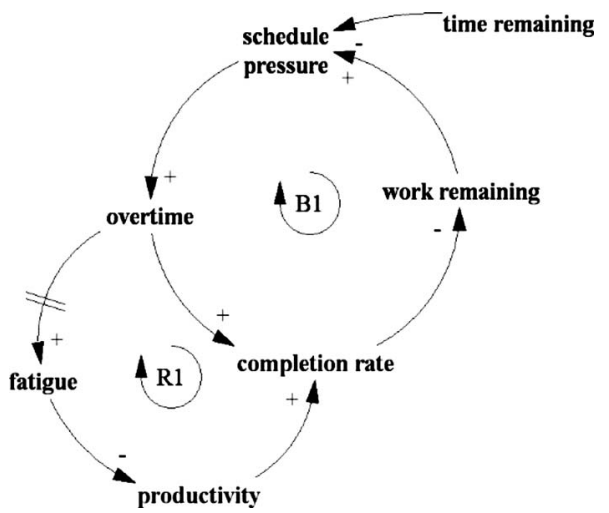

Fig. 1. Example of causal loop diagram (Sterman 2000)

remaining before the deadline. When schedule pressure builds up and engineers work overtime, these engineers increase the rate at which they complete their tasks, cut the backlog of work, and relieve the schedule pressure (Balancing Loop B1). However, if the work week is prolonged, fatigue sets in and productivity suffers. As productivity falls, the task completion rate drops; this again increases schedule pressure (Reinforcing Loop R1).

\section{Survey}

To identify the underlying causes of the aforesaid problems, 41 interviews were conducted with 13 public owners and 28 contractors (including architects). The results of these surveys were used to identify the model variables and their casual relationships; these results will be discussed in the following section. On average, the public owners surveyed have had 13.31 years of experience, while the contractors have had over 15 years. With direct regard to DB experience, public owners averaged at 3.15 projects, while contractors averaged at 8.25 projects.

Furthermore, $84.62 \%$ of the public owners have worked in construction for over 10 years, whereas $100 \%$ of the contractors possess over 15 years of experience as construction professionals. In particular, the respondents' experience, in number of DB projects, is as follows: $69.32 \%$ of the owners have had less than 3 , $23.08 \%$ have had $3-5,8 \%$ have had $6-8$, and $0 \%$ have had over 9. On the other hand, $32.14 \%$ of the contractors have had less than three DB projects, $14.29 \%$ have had 3-5, 7.14\% have had $6-8$, and $46.43 \%$ have had more than 9. Among the contractors, the weighted mean number of DB projects is 8.25 , while that among the public owners is 3.15 . The average construction industry career length is over 16 years among the contractors and is 13.31 years among the public owners. It was also determined that public owners have had insufficient DB project experience relative not only to their career lengths, but also relative to the contractors' DB experience.

Further, $46.15 \%$ of the owner group assumes that the DB delivery system will yield advantages in terms of time saving and high quality work. 23.08 and $30.77 \%$ of the respondents from the owner group answered that they base this judgment on successful cases in other countries and expert opinion, respectively. A total of $58.54 \%$ of the respondents cited the high cost of responding to request for proposal (RFP) as the determining factor in the reality that only a few major construction companies are able to assume the high risks entailed in bidding on a DB project. Moreover, in Korea, DB bidding requires a DB team comprised of a construction company and an architectural firm, and generally, the con- struction company incurs the cost of preparing the bid Furthermore, $56.10 \%$ of the respondents asserted that high levels of design input/prescriptive specifications cause less extensive design innovation, while $58.54 \%$ of those surveyed responded that design input and specifications must be decreased (see Table 4).

\section{System Dynamics Model Development}

As seen in Fig. 2, based on the aforesaid relationship between the three major factors and related factors-number of $D B$ projects, number of $D B$ teams attending bid (i.e., bidding competition), and $D B$ performance - a conceptual model of DB growth was developed to analyze the specific characteristics, and the phenomenon, of the present DB delivery system. If DB performance is high, as a consequence of increasing new entry into the market (Songer et al. 1994, 1997; Ndekugri and Turner 1994), this will result in an increase in bidding competition (i.e., the number of DB teams attending bid), which will subsequently cause the number of DB projects to increase. Then, an increase in the number of DB projects will generate an influx of new bidders into the DB market. Thus, the relationship between these three factors is a reinforcing feedback.

To develop this conceptual model, model variables were extracted, in detail, for each component. Then, the relationships (positive or negative) among these variables were identified based on previous research and survey results (Table 5). In addition, other factors with causal links were supplemented by examining the Korean government's efforts to address the issues of subjective evaluation and the diversity of DB contractors (Table 5). Ultimately, the system dynamics model was developed with the following process: (1) conceptual model building; (2) extracting and identifying the relationships between the model variables; (3) developing partial models in detail and verifying these with the qualitative data collected from the interviews, and then structuring the full model with all of these parts; and (4) summarizing all the variables, their relationships, and their basis.

\section{Number of DB Projects}

Based on the questionnaire and literature review, it can be concluded that the number of DB projects is determined by owners' expectation of $D B$ performance, the number of large-scale projects, and negative public opinion of $D B$. The number of largescale projects not only increases the number of DB projects, but also heightens owners' expectation of DB performance. Furthermore, as large-scale projects are more complex than small and medium-sized projects, owners' dependency on DB will increase as more efficient organizational collaboration is made possible by $\mathrm{DB}$, thus enabling the transfer of all design and construction risks from the owner to the contractor. Moreover, it was found that both public owners and contractors believe that the DB delivery system will outperform DBB in quality $(46.34 \%$ of the owner group) and time saving (36.59\% of the owner group). However, negative public opinion of DB does cause owners to adopt fewer DB projects. In fact, in Korea, there has been a strongly negative public sentiment toward DB concerning the lack of diversity among bidders and successful DB teams.

Furthermore, in the Korean construction industry, owners' expectation of DB performance is considered to be the most influential factor impacting the increase in the number of DB projects. As seen in Fig. 3, owners' expectation of DB performance is based on their experience with successful DB projects. However, 
Table 4. Survey Results on the Causes of DB Characteristics in Korea

\begin{tabular}{|c|c|c|c|}
\hline Questions and answers & $\begin{array}{l}\text { Owner } \\
(\%)\end{array}$ & $\begin{array}{l}\text { Contractor } \\
(\%)\end{array}$ & $\begin{array}{l}\text { Total } \\
(\%)\end{array}$ \\
\hline \multicolumn{4}{|l|}{ 1. What is the advantage of $\mathrm{DB}$ over DBB? } \\
\hline Time saving & 46.15 & 32.14 & 36.59 \\
\hline Cost saving & 0.00 & 14.29 & 9.76 \\
\hline High quality & 46.15 & 46.43 & 46.34 \\
\hline No advantages & 7.69 & 7.14 & 7.32 \\
\hline \multicolumn{4}{|l|}{ 2. What is the basis of your judgment for question \#1? } \\
\hline Own experience & 46.15 & 75.00 & 65.85 \\
\hline Successful case of other countries & 23.08 & 7.14 & 12.20 \\
\hline Expert opinion & 30.77 & 14.29 & 19.51 \\
\hline Other opinion & 0.00 & 3.57 & 2.44 \\
\hline \multicolumn{4}{|l|}{ 3. Why do only a few organizations attend DB bidding? } \\
\hline Only large architectural firms can make winning designs & 53.85 & 14.92 & 26.83 \\
\hline $\begin{array}{l}\text { The high cost of responding to RFPs limits the number of construction companies that can incur such } \\
\text { a high risk }\end{array}$ & 30.77 & 71.43 & 58.54 \\
\hline Both & 15.38 & 14.92 & 14.63 \\
\hline Other opinion & 0.0 & 0.0 & 0.0 \\
\hline \multicolumn{4}{|l|}{ 4. Why is the cost of responding to DB RFPs high? } \\
\hline Because of the normal burden entailed & 76.92 & 57.14 & 63.41 \\
\hline Because of illegal lobbying activities & 23.08 & 42.86 & 36.59 \\
\hline Other opinion & 0.0 & 0.0 & 0.0 \\
\hline \multicolumn{4}{|l|}{ 5. Why are only a few major contractors successful in DB and poorly distributed? } \\
\hline Because of the high cost of responding to RFPs combined with insufficient failure compensation & 53.85 & 35.71 & 41.46 \\
\hline A lack of diversity among successful DB contractors & 15.38 & 35.71 & 29.27 \\
\hline Large contractors offer excellence in design and construction & 30.77 & 28.58 & 29.27 \\
\hline Other opinion & 0.0 & 0.0 & 0.0 \\
\hline \multicolumn{4}{|l|}{ 6. What is the influence of design specifications on design innovation? } \\
\hline The more design input/prescriptive specifications, the less design innovation & 84.62 & 42.86 & 56.10 \\
\hline The more design input/prescriptive specifications, the more design innovation & 15.38 & 39.29 & 31.70 \\
\hline No influence & 0.0 & 17.9 & 12.20 \\
\hline \multicolumn{4}{|l|}{ 7. What is the required design, and what are the specifications, of the current DB project? } \\
\hline Will be decreased & 53.85 & 60.71 & 58.54 \\
\hline Will continue to be at the present level of detail & 15.38 & 21.43 & 19.51 \\
\hline Will be increased & 30.77 & 17.86 & 21.95 \\
\hline
\end{tabular}

as indicated by the survey results, owners lack sufficient experience with DB projects (3.15 DB projects over 13.31 years, on average). Additionally, there is currently no DB performance measuring system in place in Korea. As a result, the success of $D B$ projects has had little impact on owners' expectation of DB performance. Instead, other factors, such as expert opinion on $D B$ superiority and the successful DB cases of other countries, have taken precedence over owners' experience and number of DB projects (indeed, $353.85 \%$ of the owner respondents agreed with this). As illustrated in Fig. 2, with regard to the feedback effect associated with R1, once the number of DB projects increases, the probability that there will be more successful DB projects also increases. Accordingly, owners' expectation of DB performance increases, which can also result in an amplification of the number of DB projects adopted (Fig. 4).

\section{Number of DB Teams Attending Bid}

As summarized in Table 6, the RFP specifications of DB issued by Korean public owners for housing development projects (RFP for DB service-A housing development project in Daejoen 2007) is very detailed and prescriptive, but it is also less comprehensive in comparison to those issued by the city of Kingston (Canada) for a sports complex project (RFP for large venue entertainment centre design/build 2006) and by the University of Minnesota (United States) for a residential life and commons building project (RFP for Crookston Campus residential life and commons building 2005). As a result, preparing a bid entails prohibitive effort and expense. While Canada and the United States focus their evaluation criteria around planning and administrative is- 


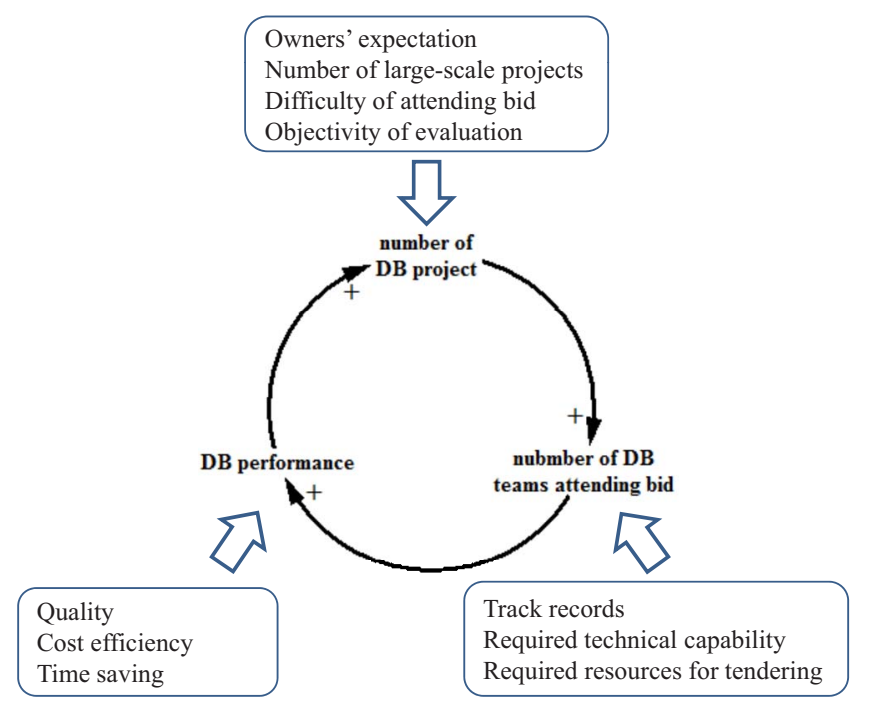

Fig. 2. Conceptual model of DB growth

sues, Korea's DB evaluation criteria rarely offers the flexibility necessary for the development of alternative designs and innovations.

In fact, such a high level of prescriptive specifications requires significant technical capability on the part of DB teams; this subsequently makes owners' consideration of track record more im- portant to the evaluation process (Puerto et al. 2008), which results in fewer companies attending DB bids (Fig. 5). A related causal factor to this is the high cost of preparing bids, which, in turn, increases the risk of failing $D B$; this risk is compounded by the low level of $D B$ failure compensation. All of these factors reduce the number of $\mathrm{DB}$ teams attending bid.

Indeed, $26.83 \%$ of the survey respondents answered that only large architect companies have the financial capability, expertise, and other necessary resources required to prepare bids, while $58.54 \%$ responded that the high cost of preparing bids limits the number of construction companies that can attend bidding. Meanwhile, there are two reinforcing feedbacks associated with the number of DB teams attending bid: R2-a and R2-b. In Korea, due to the legal stricture that construction companies cannot have an in-house design team, DB teams are normally a consortium of architectural and construction companies. Thus, the limited number of DB teams attending bid naturally leads to a relatively small number of DB teams once awarded, which results in fewer DB teams possessing the necessary track record for prequalifications (PQs) [i.e., the prerequisite for attending the next DB bidding (R2-a)]. This observation is supported by the research findings of Puerto et al. (2008). Simultaneously, the small number of DB teams attending bid triggers negative public opinion of $\mathrm{DB}$, which, in turn, makes fewer DB projects available in the market. This result in a decrease in the number of DB teams once awarded (R2-b).

On the other hand, as seen in Fig. 5, with regard to the R2-c

Table 5. Analysis of Variables and Relationships

\begin{tabular}{|c|c|c|c|c|c|c|c|c|c|c|c|c|c|c|c|c|c|c|c|c|c|c|c|}
\hline & & & & & & & & riable & and & elatio & ships & affects & Iaffec & d by, & colum & to ro & & & & & & & \\
\hline & $\mathrm{A}$ & A-1 & A-2 & A-3 & A-4 & A-5 & B & B-1 & B-2 & B-3 & $\mathrm{C}$ & C-1 & C-2 & C-3 & C-4 & C-5 & C-6 & C-7 & C-8 & $\mathrm{D}$ & D-1 & D-2 & D-3 \\
\hline A & & $1+$ & $1+$ & +1 & & & & & & & & & & & & & & & & & & & \\
\hline A-1 & +1 & & & & & & & & & & $1+$ & & & & & & & & & & & & \\
\hline A-2 & +1 & & & & & & & & & & $1+$ & & & & $1-$ & & & & & & & & \\
\hline A-3 & $1+$ & & & & & & $1+$ & & +1 & & & & & & & & & & & & & & \\
\hline A-4 & & & & & & & & & +1 & & & & & & & & & & & & & & \\
\hline A-5 & & & & & & & & & +1 & & & & & & & & & & & & & & \\
\hline B & & & & +1 & & & & $1+$ & $1+$ & $1-$ & & & & & & +1 & & & & & & & \\
\hline B-1 & & & & & & & +1 & & & & & & & & & & & & & & & & \\
\hline B-2 & & & & $1+$ & $1+$ & $1+$ & +1 & & & & & & & & & & & & & & & & \\
\hline B-3 & & & & & & & -1 & & & & $1-$ & & & & & & & & & & & & \\
\hline $\mathrm{C}$ & & +1 & $+/$ & & & & & & & -1 & & & $1-$ & $1-$ & & $+1+$ & & & +1 & & & & \\
\hline C-1 & & & & & & & & & & & & & +1 & & & & +1 & & -1 & $1+$ & & & \\
\hline C-2 & & & & & & & & & & & -1 & $1+$ & & & & & & & & & & & \\
\hline C-3 & & & & & & & & & & & -1 & & & & $1+$ & & & $1-$ & & & & & \\
\hline C-4. & & & -1 & & & & & & & & & & & +1 & & & $1+$ & & & & & $1+$ & \\
\hline C-5 & & & & & & & $1+$ & & & & $+/+$ & & & & & & & & & & & & \\
\hline C-6 & & & & & & & & & & & & $1+$ & & & +1 & & & & & & & & \\
\hline C-7 & & & & & & & & & & & & & & -1 & & & & & & & & & \\
\hline C-8 & & & & & & & & & & & $1+$ & $1-$ & & & & & & & & & & +1 & \\
\hline $\mathrm{D}$ & & & & & & & & & & & & +1 & & & & & & & & & +1 & & $1+$ \\
\hline D-1 & & & & & & & & & & & & & & & & & & & & $1+$ & & $+/$ & \\
\hline D-2 & & & & & & & & & & & & & & & +1 & & & & $1+$ & & $1+$ & & +1 \\
\hline D-3 & & & & & & & & & & & & & & & & & & & & +1 & & $1+$ & \\
\hline
\end{tabular}

Note: A. DB performance: A-1=quality; A-2 = cost efficiency; A-3=success of DB projects; A-4=expert opinion on DB superiority; A-5=successful DB cases of other countries. B. Number of DB projects: B-1 = number of large-scale projects; B-2=owners' expectation of DB performance; B-3=negative public opinion of DB. C. Number of DB teams attending bid: C-1=level of prescriptive specifications; $\mathrm{C}-2=$ required technical capability; $\mathrm{C}-3=$ risk of failing DB; C- $4=$ cost of preparing bids; $\mathrm{C}-5=$ number of DB teams once awarded; C- $6=$ design $\cos$; $\mathrm{C}-7=\mathrm{DB}$ failure compensation; $\mathrm{C}-8=$ design distinctiveness. D. Effort for improving evaluation: D-1 = pool size of evaluation committee member; D-2=lobbying; and D-3=negative public opinion of evaluation. 


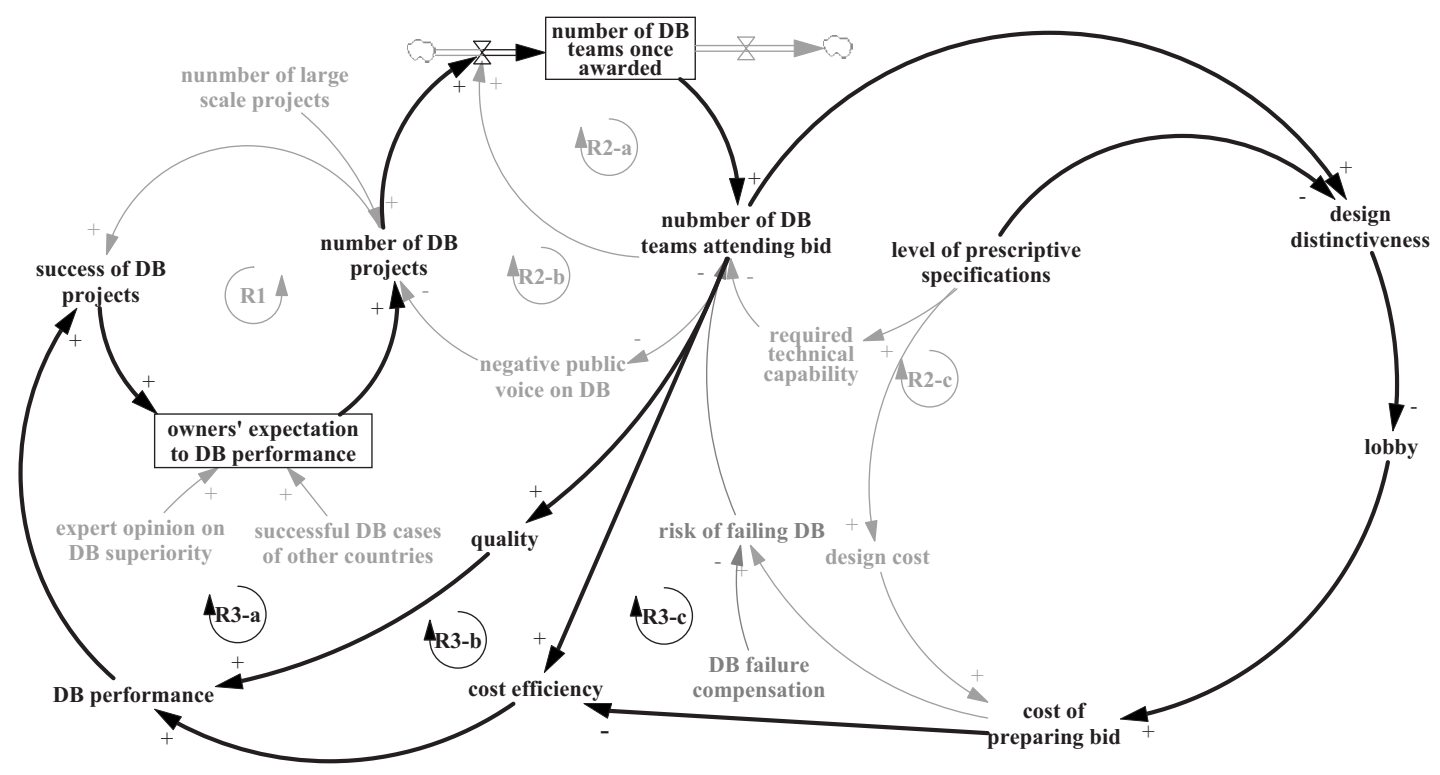

Fig. 3. DB performance

loop, the high level of prescriptive specifications for the design renders evaluation criteria that are extremely specific and quantitative. Normally, prescriptive specifications are used for traditional DBB in which the design has a maximum amount of specifications. Thus, prescriptive specifications cannot encourage innovation from offers (Molenaar et al. 1999). As a result, it becomes difficult to differentiate between teams with distinctive designs, and for this reason, $58.54 \%$ of the survey respondents argued that the level of prescriptive specifications must be reduced. Indeed, an American Association of State Highway Transportation Officials report has also observed that a small number of bidders has a negative impact on design innovation, as bidders attempt to win bids through means such as lobbying, not by competing with better designs (Levy 2006). All of these issues contribute to increasing proposal costs and consequently, project costs. As a result, bidders incur a high cost of preparing bids,

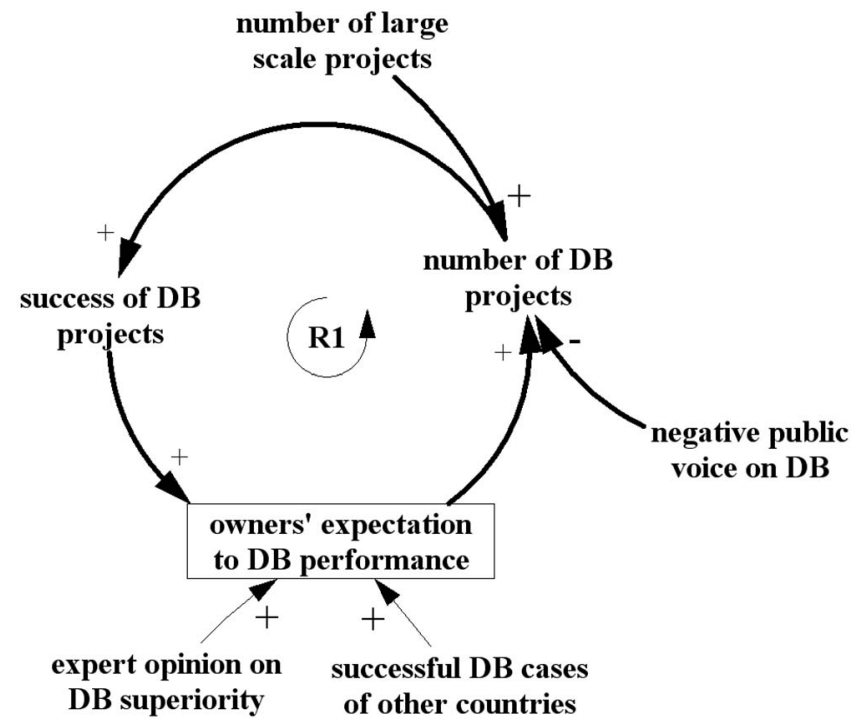

Fig. 4. Number of DB projects which increases the risk of failing DB, thereby reinforcing the trend toward a decreased number of DB teams attending bid (see R2-c in Fig. 5).

\section{DB Performance}

DB performance consists of cost efficiency, quality, and time (Molenaar et al. 1999; Puerto et al. 2008; Thomas et al. 2002; Bennett et al. 1996; Konchar and Sanvido 1998). However, time saving is excluded from the model development in this research because this feature is genuine to DB itself (LAO 2005; Gould 2005; Potts 2008; Thomas et al. 2002; Levy 2006; Songer and Molenaar 1996), and it is not easily affected by policy implementations. On the other hand, cost efficiency and quality are achieved when the competition for proposal price and quality is among bidders. According to auction theory-which is based on game theory-a bidder's optimal bid is dependent on the cost he/she sets and by the probability that he/she will win the contract, which is impacted by the distribution of cost of other firms and by the number of competitors. In general, most bidders attempting to secure public projects are adverse to risk and thus tend to bid aggressively; therefore, contract prices are more likely to be lower (Yu 2000). Consequently, if the number of DB teams attending bid is increased, the contract price will be decreased which results in better cost efficiency.

Moreover, with intensified competition, the probability of high quality will also be increased. However, in Korea, despite DB bidders having to compete with their designs and proposal prices, because these bidders tend to have similar track records, high quality and cost efficiency cannot be expected when there are less than three bidders attending the bid for a project. Therefore, an increase in the number of DB teams attending bid will have a positive effect on DB performance. This will subsequently reinforce the feedbacks of R3-a and R3-b and will also generate competition with more design distinctiveness, which reinforces the feedbacks of R3-c (Fig. 3). 
Table 6. Comparison of Requests for Proposal

\begin{tabular}{|c|c|c|c|}
\hline Countries & Program requirements & Submittal & Evaluation \\
\hline \multirow[t]{2}{*}{ Korea } & Very detailed & Very detailed & Less comprehensive \\
\hline & $\begin{array}{l}114 \text { pages of design specifications } \\
126 \text { pages of materials requirements }\end{array}$ & $\begin{array}{l}52 \text { pages of explanations } \\
\text { concerning design submittal } \\
70 \text { sets of hundreds of pages of } \\
\text { submittals requiring page limits, } \\
\text { detailed contents of proposal } \\
\text { report, etc. }\end{array}$ & $\begin{array}{l}\text { Experience, design, and proposal } \\
\text { price are evaluated based on design } \\
\text { results for } 7 \text { design parts }\end{array}$ \\
\hline \multirow[t]{2}{*}{ Canada } & Relatively simple & Relatively simple & Comprehensive \\
\hline & $\begin{array}{l}5 \text { pages of explanations focusing on } \\
\text { project program with guidelines }\end{array}$ & $\begin{array}{l}4 \text { pages of explanations concerning } \\
\text { management, schedule, design, } \\
\mathrm{O} \text { and } \mathrm{M} \text { cost, business plan summary } \\
\text { of } 15 \text { criteria, including QA/QC }\end{array}$ & $\begin{array}{l}\text { Submittal is organized into all } \\
\text { evaluation criteria so that the general } \\
\text { business plan is evaluated comprehensively }\end{array}$ \\
\hline \multirow[t]{2}{*}{ United States } & Relatively simple & Relatively simple & Comprehensive \\
\hline & $\begin{array}{l}6 \text { pages of explanations focusing on } \\
\text { project program with guidelines }\end{array}$ & $\begin{array}{l}3 \text { pages of explanations concerning } \\
\text { project team organization, resumes } \\
\text { of all on-site managers, schedule, etc., } \\
\text { business plan of the } 6 \text { categories, } \\
6 \text { copies of report }\end{array}$ & $\begin{array}{l}\text { Experience and capability of firm and } \\
\text { on-site manager, financial capability, } \\
\text { preliminary, acceptance of city goals etc., } \\
\text { comprehensive evaluation of general } \\
\text { business plan }\end{array}$ \\
\hline
\end{tabular}

\section{Unsuccessful Government Efforts}

In regard to the problem of R2-c, as shown in Fig. 6, the Korean government has attempted to improve the DB evaluation method and process. In order to prevent bidders from lobbying to the evaluation committee, the government has increased the pool size of evaluation committee members several times (from 250 in 1999 to 2,200 in 2003). However, this strategy has not been effective in reducing lobbying costs. In fact, lobbying costs have increased significantly, as potential bidders have been obliged to target thousands of potential evaluation committee members in advance (R3-a in Fig. 6). As well, the efforts made by the Korean govern- ment to enhance the prescriptive nature of design specifications by further quantifying and adding more details to the evaluation criteria has exacerbated the situation with regard to R2-c (Fig. 6).

Finally, Fig. 7 shows the full model structure, while Table 7 summarizes the variables extracted from the model and the basis of their causal relationships. This research model is used to test the policy initiatives suggested in the literature, as well as those proposed by this research. During the policy test, the writers focused on examining the effectiveness of the policies and, in this paper, will explain the model structures with regard to the relevant and current DB issues in Korea.

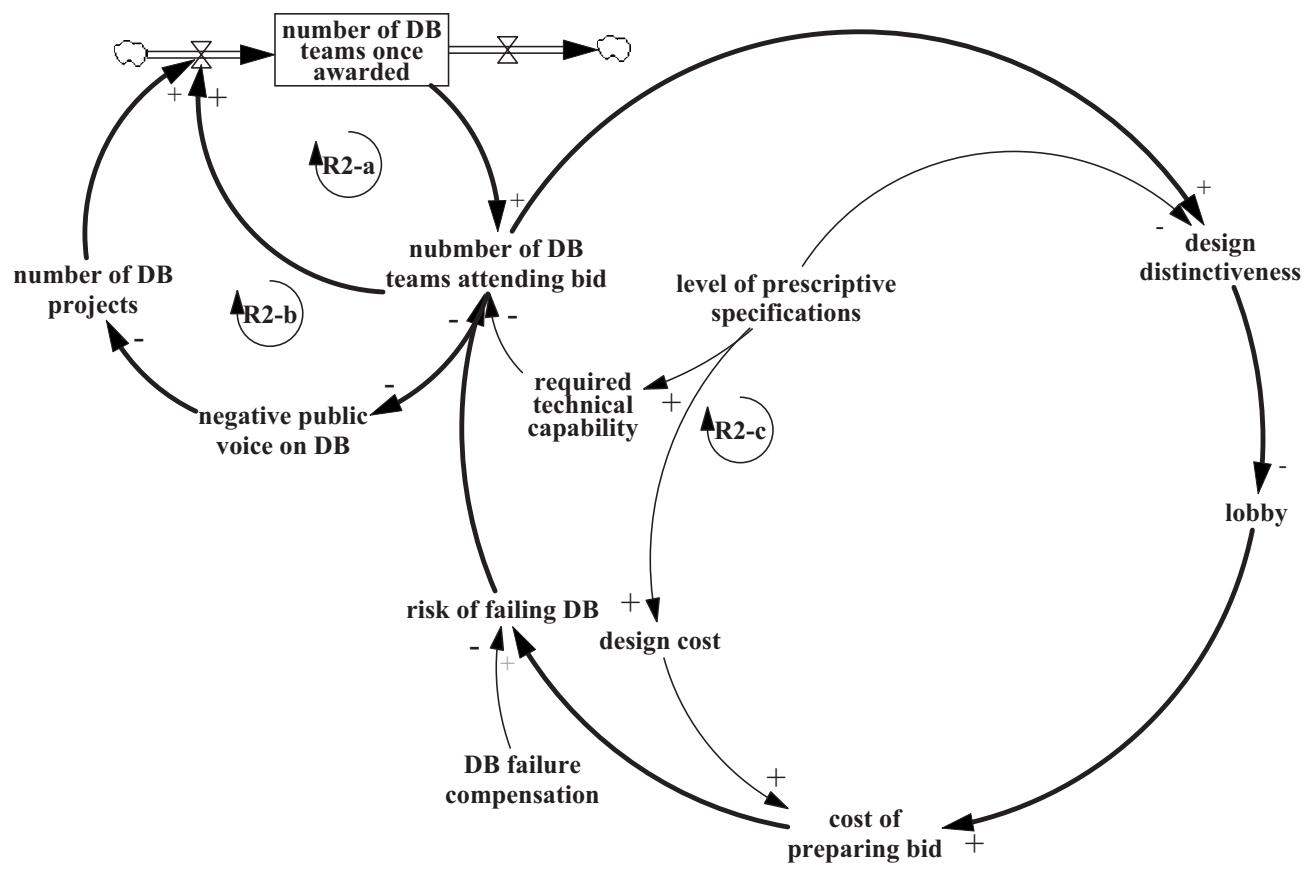

Fig. 5. Number of DB teams attending bidding 


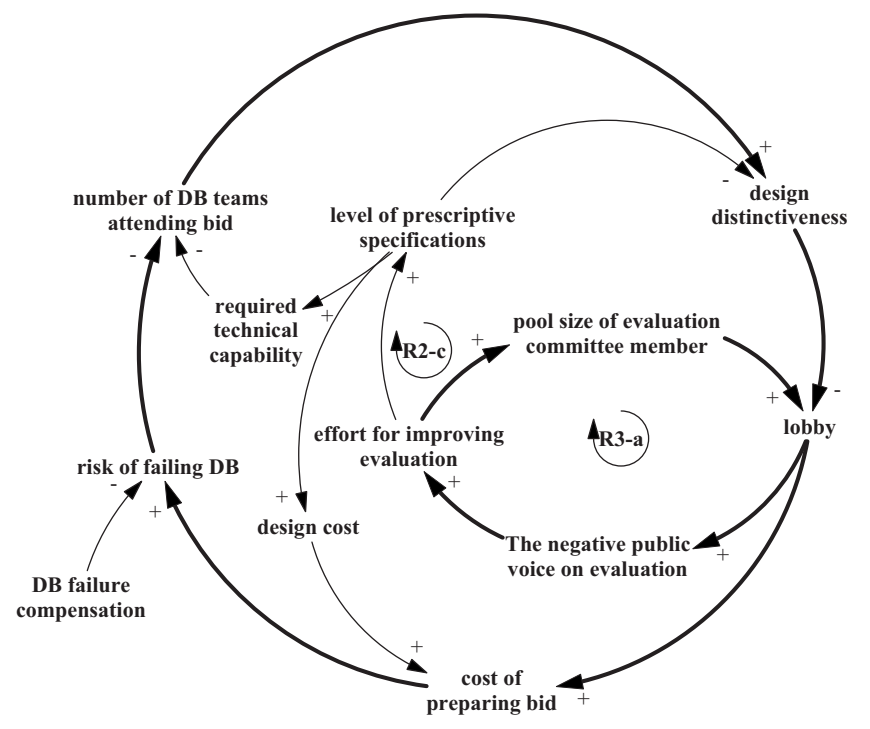

Fig. 6. Unsuccessful government efforts

\section{Policy Tests}

To validate the model, scenarios were developed and tested based on three real cases. In the first case, a policy currently being implemented by the Korean government was examined. In the second and third cases, the effectiveness of policies that have already been implemented was tested. Additionally, four approaches proposed in previous studies were tested to predict their potential effects.

\section{Increasing the Pool Size of Evaluation Committee Members (Korean Government 2003)}

As previously discussed, to achieve objective evaluation and prevent illegal activity, a quantitative expansion, which includes increasing the number of committee members and separating the divisions into two subcommittees (a technical and a evaluation committee), has been implemented by the government. Consequently, in only 4 years, there has been an approximate 20 times increase in the number of committee members (Lee et al. 2007). However, this strategy has not been effective for resolving the subjectivity issue associated with the evaluation process, and the negative reinforcing feedbacks of R2-a, R4-a, R4-b, and R4-c, are still working.

\section{Adopting “Enhanced DB" Approach (Chan 2000)}

In this approach, the term "enhanced" signifies that the client develops the design using his/her own team of consultants; then, the client requires tenders to submit a conforming bid based on this design. This approach has the advantages of the fast track method, but it also limits competition. Thus, this policy can have a positive impact on DB performance by reducing construction time (Chan 2000). This effect could improve DB performance and owners' expectation of DB performance, which, to a certain extent, increases the number of DB projects, number of DB teams once awarded, and number of DB teams attending bid. However, limited competition lessens the number of DB teams attending bid; therefore, adopting the "enhanced DB" approach will still have a negative impact on quality and cost efficiency by fuelling the reinforcing loops R2-a and R2-b, R3-a-R3-c, and R4-c (see Fig. 8).

\section{Developing DB Proposal Evaluation Plan (Puerto et al. 2008)}

This approach can ensure that the actual weighting given to the DB proposal evaluation criteria match the project's demands. Consequently, it can help to enhance DB performance and owners' expectation of DB performance, thus intensifying the related loops of R1 and R3-a. However, when applied to the current situation in Korea, in which prescriptive specifications of DB projects are used without being transformed into performance specifications, this remedy results in extremely specific evaluation criteria, which lessens the will of bidders to be innovative. Developing a DB proposal evaluation plan without performance specifications increases the degree of technical capability required to satisfy project requests; this will have a negative impact on the number of DB teams attending bid. Then, the vicious loops re-

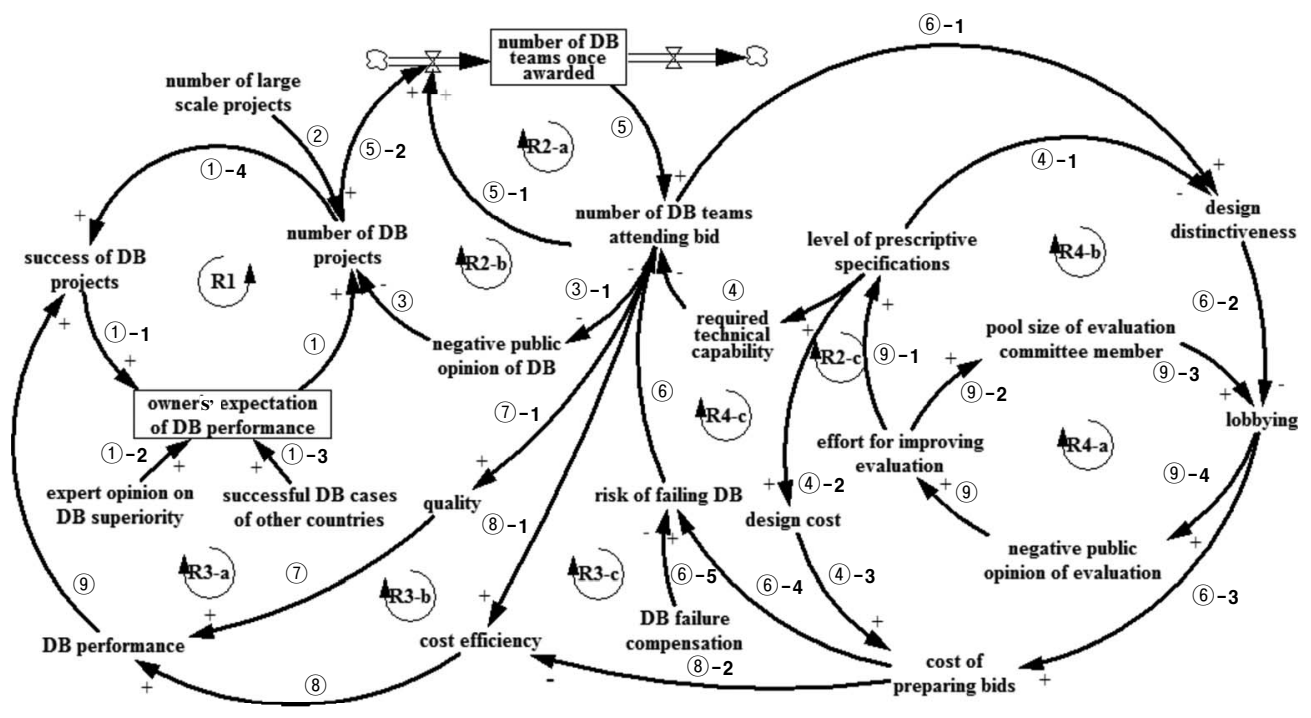

Fig. 7. Full DB model 
Table 7. Model Variables and Basis of Causal Links

\begin{tabular}{|c|c|c|}
\hline Variables & Link number & Basis \\
\hline $\begin{array}{l}\text { A. DB performance } \\
\text { A-1. Quality } \\
\text { A-2. Cost efficiency } \\
\text { A-3. Success of DB projects } \\
\text { A- } 4 \text {. Expert opinion of DB superiority } \\
\text { A-5. Successful DB cases of other countries }\end{array}$ & $\begin{array}{l}\text { (7), (8), (9) } \\
\text { (7), (7)- } 1 \\
\text { (8), (8) }-1,2 \\
\text { (1) }-1,4, \text { (9) } \\
\text { (1) }-2 \\
\text { (1) }-3\end{array}$ & $\begin{array}{l}\text { (1) (1), (3), (5), (7), (8) and (2) } \\
\begin{array}{l}\text { (1) (1), (5), (8) and (2) } \\
\text { (1) (1), (5), 8) } \\
\text { (1) (1), (5), 8, (2) } \\
\text { (2) }\end{array}\end{array}$ \\
\hline $\begin{array}{l}\text { B. Number of DB projects } \\
\text { B-1. Number of large-scale projects } \\
\text { B-2. Owners' expectation of } \\
\text { DB performance } \\
\text { B-3. Negative public opinion of DB }\end{array}$ & $\begin{array}{l}\text { (1), (1) }-4, \text { (2), (3), (5) }-2 \text {, } \\
\text { (2) } \\
\text { (1), (1) }-1,2,3 \\
\text { (3), (3) }-1\end{array}$ & $\begin{array}{c}\text { (1) (1), (4), (6), (7), (8), (10, (12), (2), (3) } \\
\text { (3) } \\
\text { (2) } \\
\text { (3) and (4) }\end{array}$ \\
\hline $\begin{array}{l}\text { C. Number of DB teams attending bid } \\
\text { C-1. Level of prescriptive specifications } \\
\text { C-2. Required technical capability } \\
\text { C-3. Risk of failing DB } \\
\text { C-4. Cost of preparing bids } \\
\text { C-5. Number of DB teams once awarded } \\
\text { C-6. Design cost } \\
\text { C-7. DB failure compensation } \\
\text { C-8. Design distinctiveness }\end{array}$ & $\begin{array}{c}\text { (3)- }-1 \text {, (4), (5), (5) }-1 \text {, } \\
\text { (6), (6) }-1,(7)-1 \text {, (8) }-1 \\
\text { (4), (4) }-1, \text { (4) }-2 \text {, (9) }-1 \\
\text { (4) } \\
\text { (6), (6) }-4 \\
\text { (4) }-3 \text {, 6) }-3, \text { (6) }-4, \text { (8) }-2 \\
\text { (5), (5) }-1 \text {, (5) }-2 \\
\text { (4) }-2,3 \\
\text { (6) }-5 \\
\text { (8), (8) }-1,2, \text { (9) }\end{array}$ & $\begin{array}{l}\text { (1) (6), (7), (9), (12), (13) and (2) } \\
\text { (1) (2), (5), (7), (2), and (5) } \\
\text { (1) (11, (12) and (2) } \\
\text { (2) } \\
\text { (1) (4), (12), } \\
\text { (1) (13), and (2) } \\
\text { (4) and (5), } \\
\text { (1) (12) and (4) } \\
\text { (1) (2), (6), (7), (12) and (2) }\end{array}$ \\
\hline $\begin{array}{l}\text { D. Effort for improving evaluation } \\
\text { D-1. Pool size of evaluation committee } \\
\text { member } \\
\text { D-2. Lobbying } \\
\text { D-3. Negative public opinion of evaluation }\end{array}$ & $\begin{array}{l}\text { (9), (9) }-1,2 \\
\text { (4) }-1, \text { (6) }-1,2 \\
\text { (6) }-2,3(9)-3,4 \\
\text { (9), (9) }-4\end{array}$ & $\begin{array}{l}\text { (4) } \\
\text { (3) and (4) } \\
\text { (1) 6), (2), (4), } \\
\text { and (4), }\end{array}$ \\
\hline
\end{tabular}

Note: (1) Derived from previous research; (1) Ndekugri and Turner (1994), (2) Bennett et al. (1996), (3) Songer et al. (1994), (4) Seely (1997), (5) Konchar and Sanvido (1998), (6) Molenaar and Songer (1998), (7) Molenaar et al. (1999), (8) Thomas et al. (2002), (9) Yu (2000), (10 Kim et al. (2007), (11) LAO (2005), (11) Levy (2006), and (12) Puerto et al. (2008); (2) derived from survey results; (3) derived from empirical data; (4) real Korean case; and (5) derived from analysis of RFPs.

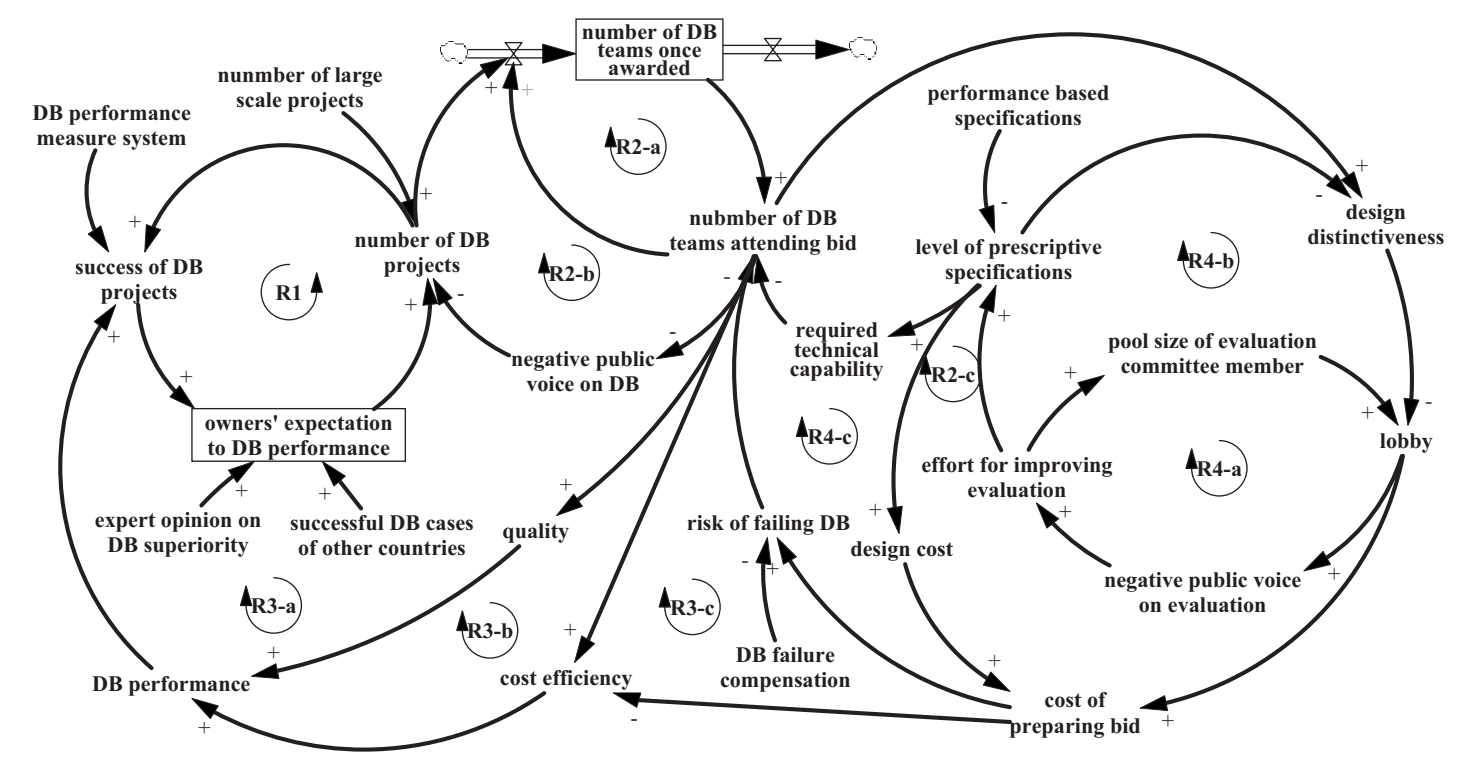

Fig. 8. Policy suggestions 
lated to the number of DB teams attending bid (R2-a, R2-b, R2-c, and R4-c, as seen in Fig. 8) will not only still be activated, but also more accelerated.

\section{Decreasing DB Projects by Increasing Budget Standards (Lee 2006)}

To address a marketplace dominated by a few major contractors, one policy proposed by Lee is to increase budget standards (Lee 2006). This policy was implemented to reduce the volume of DB projects rather than to enhance the current DB system. However, as discussed with regard to R2-a, this measure only further accelerated the dominance of a select group of major contractors. This effect can also be verified by the fact that a similar policy, triggered by negative public opinion of DB (R2-b in Fig. 8), has had a negative impact on the diversity of DB teams.

\section{Increasing DB projects by Dividing Large Projects into Smaller Projects (Lee 2006)}

This measure-increasing the number of DB projects by dividing large projects into smaller ones-might, of course, encourage small and medium-sized contractors to enter into the bidding process. However, this strategy would also result in owners having to manage plenty of administrative work and an increased probability of conflict among various contractors. Thus, this measure cannot be considered an effective alternative, as it would be unreasonable to expect that the potential advantages of DB could be achieved.

\section{Introducing Bridging DB (Lee 2006)}

Another strategy referred to as Bridging DB (or, design-DB) is a delivery system whereby an owner contracts with an architect to create a set of preliminary design documents to be used in soliciting bids in the market (Levy 2006). In Bridging DB, the owner invites the architect to suggest preliminary design changes, or he/she allows the submission of a value engineering proposal that will not entail a significant redesign cost. Due to its unique features, Bridging DB can be effective in enhancing the design quality of DB projects. Nevertheless, if the same design requirements are given to those bidders attending the main round of bidding, the vicious loop effects will still be activated (R2-a, R2-b, R2-c, R4-a, R4-b, and R4-c, as seen in Fig. 8), and the current problems will persist.

\section{Decreasing the Number of Committee Members by Establishing a Long-Standing Specialized Evaluation Committee (Kim et al. 2007)}

This measure could eventually have a positive long-term impact, as it eliminates the vicious loop effect of R4-a (Fig. 8) by disconnecting the causal link between efforts to improve evaluation and the size of the evaluation committee membership pool. It could also help reduce the costs of DB bid preparation. However, with the currently high level of prescriptive specifications, contractors would have to continue to resort to lobbying as a means of differentiating themselves from their competitors. In this case, corrupt and/or subjective evaluation will continue to persist, as will the critiques such methods raise.

\section{Policy Suggestions}

So far, the effectiveness of policy initiatives of real cases and suggestions made by other researchers has been tested. It was found that among these initiatives, establishing a long-standing specialized committee and introducing Bridging DB could help in mitigating current DB issues in the Korean construction industry. However, it is unlikely that these two measures alone can completely solve the aforementioned problems. Furthermore, these two initiatives would not be sufficiently influential to reverse the direction of the inertia fueled by the reinforcing feedbacks (R2-a, R2-b, R2-c, R4-a, R4-b, and R4-c, as seen in Fig. 8).

Based on the policy insights and implications obtained throughout the development of a system dynamics model, this section suggests three fundamental policy initiatives that can mitigate the current DB issues, thereby allowing for the potential advantages of DB to be fully achieved (Fig. 8).

\section{Changing Prescriptive Design Specifications to Performance-Based Specifications}

The research model demonstrates that as there are no marketmechanism based balancing loops to help alleviate the current DB issues, there are only reinforcing feedbacks. In particular, many reinforcing feedbacks, such as R2-c, R4-a, R4-b, and R4-c (Fig. 8), are associated with high bidding costs and prescriptive design specifications. With strong market governance, these reinforcing feedbacks maintain their inertia, preventing small and mediumsized contractors from entering the DB market.

Upon a closer examination of the model, the root cause of the vicious feedback effects can be identified as the high level of prescriptive specifications. From an owner's perspective, such detailed and strict design requirements can be viewed as advantageous in terms of simplifying project management. However, the current detailed specifications do not work as expected and have been restrictive, preventing many qualified small and mediumsized companies from entering the DB market and negating the enhancement of innovation (Molenaar and Songer 1998). On the other hand, as confirmed by previous studies, an RFP written with performance specifications results in the delivery of a better DB product and encourages innovation (Songer et al. 1994; Molenaar and Songer 1998).

To fundamentally remedy the aforementioned problems, this research proposes the introduction of performance-based specifications into the DB bidding process, as they could lower high bidding costs (Fig. 8). That said, it should be noted that, given the associated feedbacks, it will take time to reverse the current situation. In particular, if owners persist in requiring good track records during the $\mathrm{PQ}$ process, the R2-a loop effect will continue to govern the market, at least for the time being (Fig. 8).

\section{Increasing Failure Compensation}

In addition to the introduction of performance-based specifications, increasing DB failure compensation could fuel beneficial market changes (Fig. 8). If failure compensation is increased, more technically - although not necessarily financially-capable small and medium-sized DB teams will be able to participate in the bidding process. As this policy aims at increasing the coverage of failure compensation, not the absolute money amount (note that the current high bidding costs can also be diminished by performance-based specifications), it can also be executed without burdening the project budget. 


\section{Establishing a Performance Measure System}

In order for the proposed performance-based specifications policy to be effective, a $D B$ performance measure system - which has already been used in the United States (Thomas et al. 2002) and the United Kingdom (Building on success-The future strategy for achieving excellence in construction 2003) — must be established. This system would not only be used as a standard indicator of DB performance, but also as a tool for tracking and managing construction data.

In addition, as has already been discussed with regard to R1, the Korean government's expectations of DB performance have not been predominantly based on Korea's own DB successes but on the successful DB cases of other countries. In such a context, once a performance measure system is established together with performance-based specifications, it will be possible to properly and accurately measure the performance of DB projects. This will then trigger desirable feedback processes in the DB market (i.e., R3-a, R3-b, and R3-c, as seen in Fig. 8). Then, as good DB performance is yielded and measured accurately with a proper measuring system, owners' expectation of DB performance will increase. This will result in more projects being delivered using DB and will increase the probability of more diversified DB teams, which will subsequently increase DB performance by enhancing either quality (R3-a) or cost efficiency (R3-b). Meanwhile, an increased number of DB teams attending bid can also lead to a decreased cost of preparing bid as well as an increased cost efficiency and enhanced DB performance (R3-c).

Along with the three policy initiatives proposed in this study, two previously suggested and effective policies will also help owners achieve the advantages inherent in DB. Together, these policy initiatives are as follows:

1. Changing Prescriptive Design Specifications to PerformanceBased Specifications;

2. Increasing Failure Compensation;

3. Establishing a Performance Measure System;

4. Introducing Bridging DB; and

5. Decreasing the Number of Committee Members by Establishing a Long-Standing Specialized Evaluation Committee.

\section{Conclusions}

In recent years, the DB delivery system has been implemented more and more because of its advantageous features. However, this system has also been much criticized for being based on subjective evaluation and for being limited in its accessibility to small and medium-sized contractors. In Korea, since the introduction of DB in 1975, the number of DB projects has steadily increased. Nevertheless, only a select group of contractor-led DB teams has been able to participate in the bidding process and has thus increasingly dominated the DB market. Consequently, public owners in Korea have rarely benefited from the potential advantages of DB.

To address these significant issues, the present research has aimed at analyzing the characteristics of Korea's DB delivery system, while suggesting alternative DB policy initiatives that are founded on system dynamics modeling. The delivery trends in the public sector and the causal relationships among DB characteristics were analyzed through surveys. Then, based on the research findings, a system dynamics DB model was developed to interrogate the issues raised in the surveys and the literature review, and to test the effectiveness of the policies proposed elsewhere and in this research. Accordingly, five policy initiatives-which are expected to alleviate current DB issues while enhancing DB performance-were suggested.

Finally, the research findings detailed in this paper also emphasize how a qualitative simulation method can effectively assist decision-makers involved in the process of construction policymaking. In addition, after the appropriate customization processes, this research could be beneficially applied to the industry settings of different countries.

However, as this research is based on limited data and only actual cases in Korea, it must be further developed with the analysis of a wider range of data. As well, a customized model, which takes international perspectives and experience into account, must be constructed.

\section{Acknowledgments}

This research was supported by a grant (Grant No. R\&D06CITA03) from the Innovative Construction Cost Engineering Research Center, and by a grant (Grant No. 05CIT-01) from the Construction Technology Innovation Program which is funded by the Ministry of Construction and Transportation (government of Korea).

\section{References}

Bennett, J., Pothecary, E., and Robinson, G. (1996). Design and building a world class industry: Reading design-build forum, Center for Strategic Studies in Construction, Univ. of Reading, Reading, U.K.

Chan, A. P. C. (2000). "Evaluation of enhanced design and build system-A case study of a hospital project." Constr. Manage. Econom., 18, 863-871.

Gould, F. R. (2005). Managing the construction process, 3rd Ed., Prentice-Hall, Upper Saddle River, N.J.

Kim, Y. M., et al. (2007). "The prerequisites for improving construction policy in public sector." Research Forum of Public Construction Policy, KICEM, 169-171, 415-416.

Konchar, M., and Sanvido, V. (1998). "Comparison of U.S. project delivery system." J. Constr. Eng. Manage., 124(6), 435-444.

Lee, H. S., et al. (2007). "Analyzing characteristics of design-build delivery system in Korea using system dynamics modeling." Korea Institute of Construction Engineering and Management, 8(5), 119-132.

Lee, S. H. (2006). The prerequisites for developing turn-key system, Construction \& Economy Research Institute of Korea, Seoul, Korea.

Levy, S. M. (2006). Design-build, McGraw-Hill, New York.

Molenaar, K. R., et al. (1999). "Public-sector design/build evolution and performance." J. Manage. Eng., 15(2), 54-62.

Molenaar, K. R., and Songer, A. D. (1998). "Model for public sector design-build project selection." J. Constr. Eng. Manage., 120(6), 467-479.

Natkin, K. H. (1994). "Legal aspect of design/build." AIAA J., 83(9), $125-127$.

Ndekugri, I., and Turner, A. (1994). "Building procurement by design and build approach." J. Constr. Eng. Manage., 120(2), 243-256.

Office of Government Commerce. (2003). Building on success-The future strategy for achieving excellence in construction, London.

Park, C. K. (2006). Characteristics of construction environment in Korea: The paper of 4th discussion, Forum of Research for Developing Government Construction Regulation, Seoul, Korea.

Potts, K. (2008). Construction cost management, Taylor and Francis, London.

Puerto, C. L., et al. (2008). "Comparative analysis of owner goals for design/build projects." J. Manage. Eng., 24(1), 32-39. 
RFP for Crookston Campus residential life and commons building. (2005). Regents of the Univ. of Minnesota, Univ. of Minnesota.

RFP for DB service-A housing development project in Daejoen. (2007). Korea National Housing Corporation, Seoul Korea.

RFP for large venue entertainment centre design/build. (2006). City of Kingston, Office of the City Clerk, Ontario, Canada.

Rye, J. B. (2006). Interpellation of Parliamentary Inspection Report of Ministry of Construction and Transportation, 〈http://www.mofe.go.kr/ public/ninfo1.php $\rangle$ (Dec. 1, 2006).

Seeley, I. H. (1997). Quantity surveying practice, 2nd Ed., Antony Rowe Ltd., 97-100.

Seo, Y. C. (2003). Method of Choosing Delivery System in Big Construction Project, the 13th CM Forum, Korea Institute of Construction Engineering and Management, 16-17.

Songer, A. D., et al. (1994). "Process model for public sector design- build planning." J. Constr. Eng. Manage., 120(4), 857-874.

Songer, A. D., et al. (1997). "Project characteristics for successful publicsector design-build.” J. Constr. Eng. Manage., 123(1), 34-40.

Songer, A. D., and Molenaar, K. R. (1996). "Selecting design-build: Public and private sector owner attitude." J. Manage. Eng., 12(6), 47-53.

Sterman, J. (2000). Business dynamics: System thinking and modeling for a complex world, McGraw-Hill, New York.

Thomas, S. R., et al. (2002). Measuring the impact of the delivery system on project performance-design-build and design-bid-build, National Institute of Standards and Technology (NIST), Austin, Tex.

White paper on construction. (2000-2006). Construction Association of Korea, Seoul, Korea.

Yu, J. (2000). Introduction to auction theories and empirical method for analyzing bidding behaviors, CERIK, Korea. 